\title{
11. Abbildungen
}

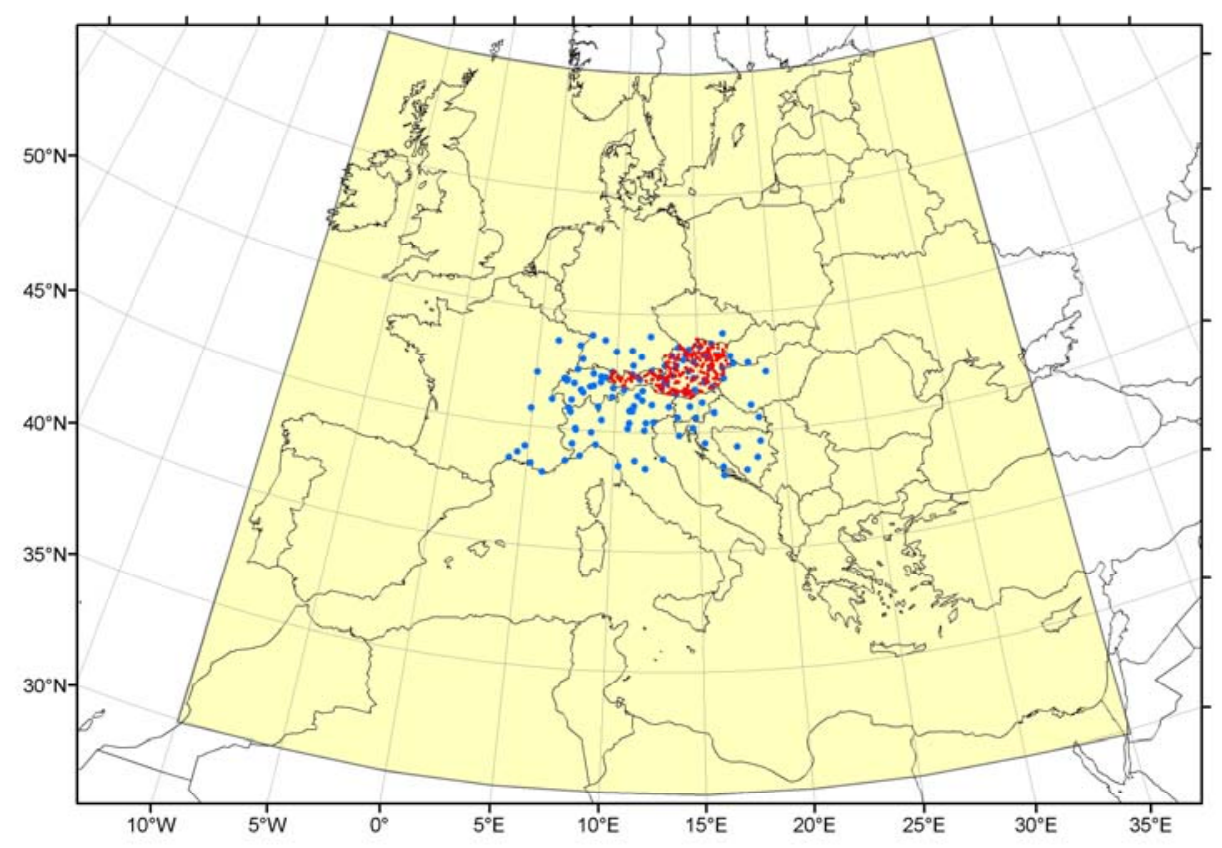

Fig. 1: Stationsnetze, die in dieser Arbeit verwendet werden: die roten Punkte markieren das phänologische Stationsnetz der ZAMG, die blauen die HISTALP Temperaturstationen und die beige schattierte Fläche kennzeichnet das Gitter der CRU Temperaturen, das zur Berechnung der Temperaturgradienten verwendet wurde.

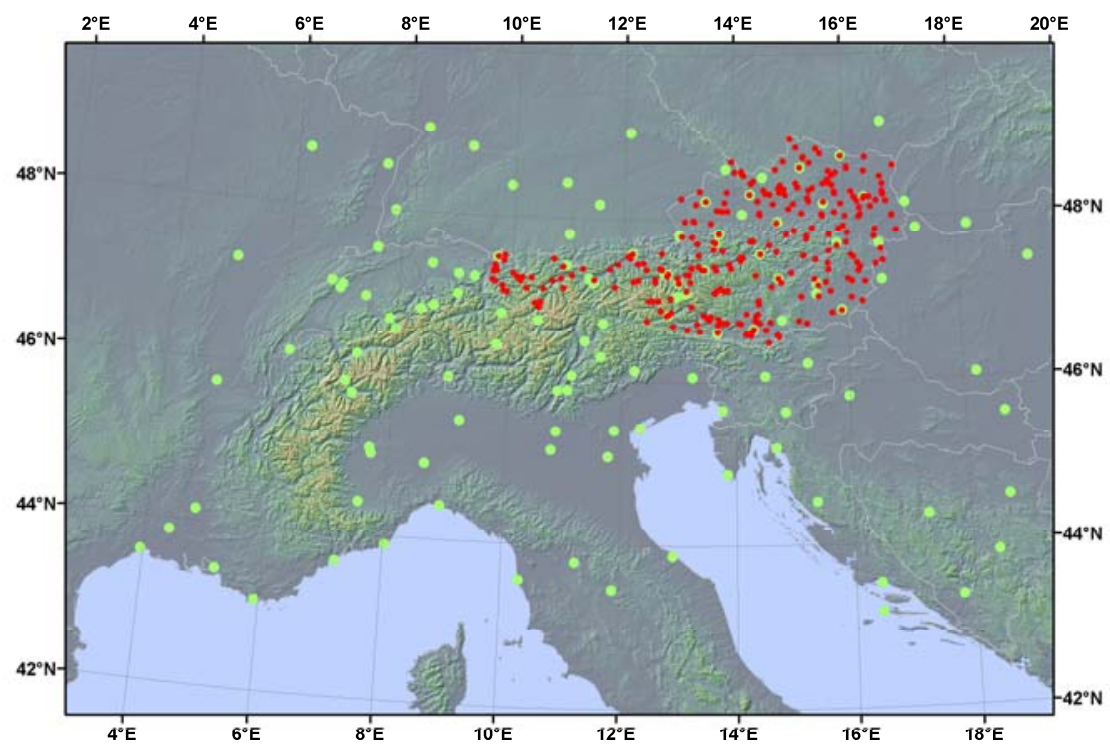

Abb. 2: Wie Abb. 1, aber mit einem vergrößerten Ausschnitt des ZAMG und des HISTALP Stationsnetzes. 


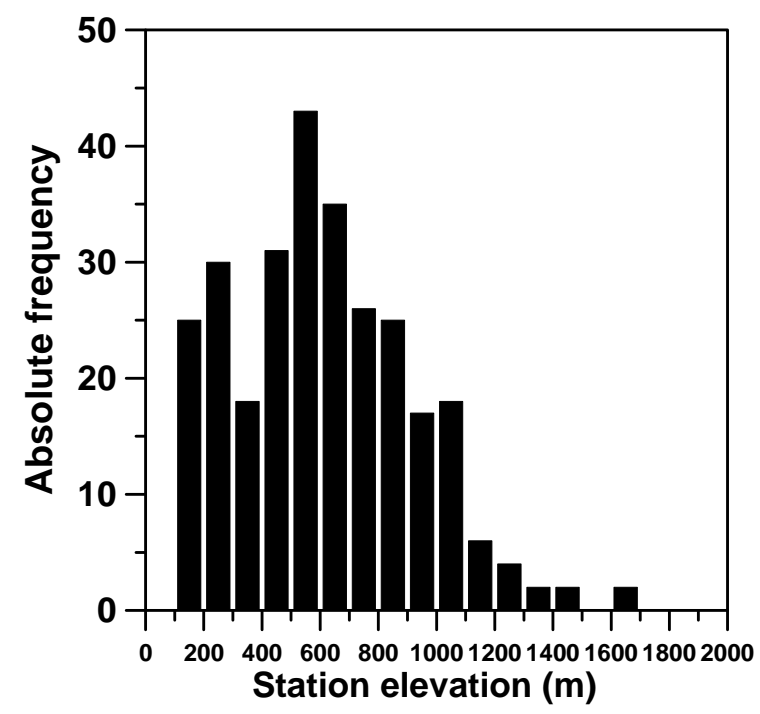

Abb. 3: Histogramm der Stationshöhen des phänologischen Stationsnetzes der ZAMG.
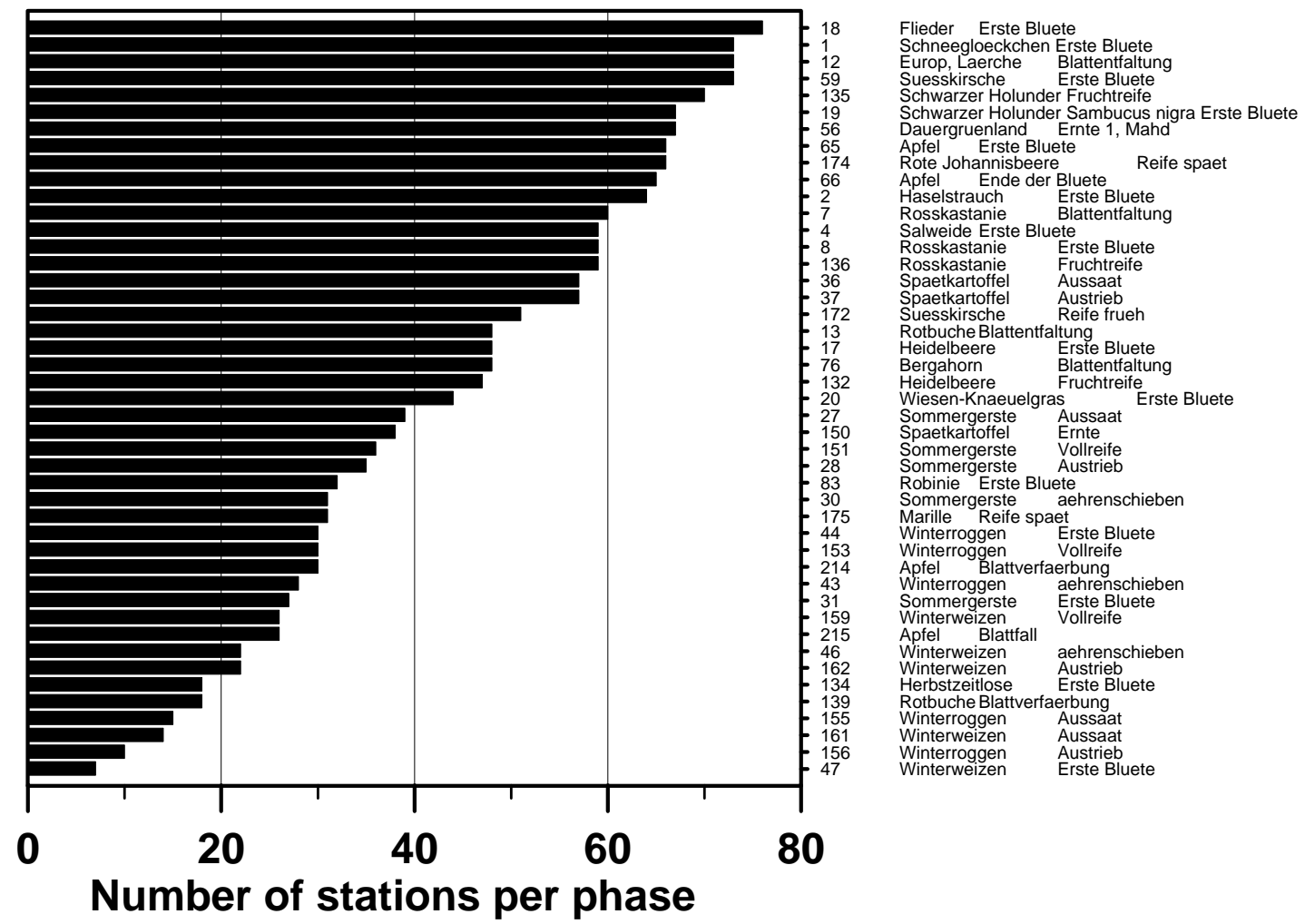

Schneegloeckchen Erste Bluete
Europ, Laerche Blattentfaltun

Suesskirscher Erste Bluete

Holunder Sambucus nigra Erste Bluete Davergruenland 1 Ermte 1, Mahd

Rote Johannisbeere Reife spae

Haselstrauch der Bluete Blattentfaltung

Rosskastanie Erste Bluete

Fruchtreife

-Knaeuelgras

Aussaat

Sommergerste Bluete

Winterroggen aehrenschieben

Sommergerste Erste Bluete

Apfel Blattfall

Herbstzeitlose Erste Bluet

Winterroggen Aussaa

$\begin{array}{ll}\text { Winterroggen } & \text { Austrieb } \\ \text { Winterweizen } & \text { Erste Blue }\end{array}$

\section{$60 \quad 80$ \\ Number of stations per phase}

Abb. 4. Zahl der Stationen pro Phase. Nachdem das Kriterium, dass von mindestens 20 Beobachtungen pro Phase und Station im Zeitraum von 1951 - 2005 vorliegen müssen, angewendet worden war, blieben 45 der 244 Phasen übrig. 


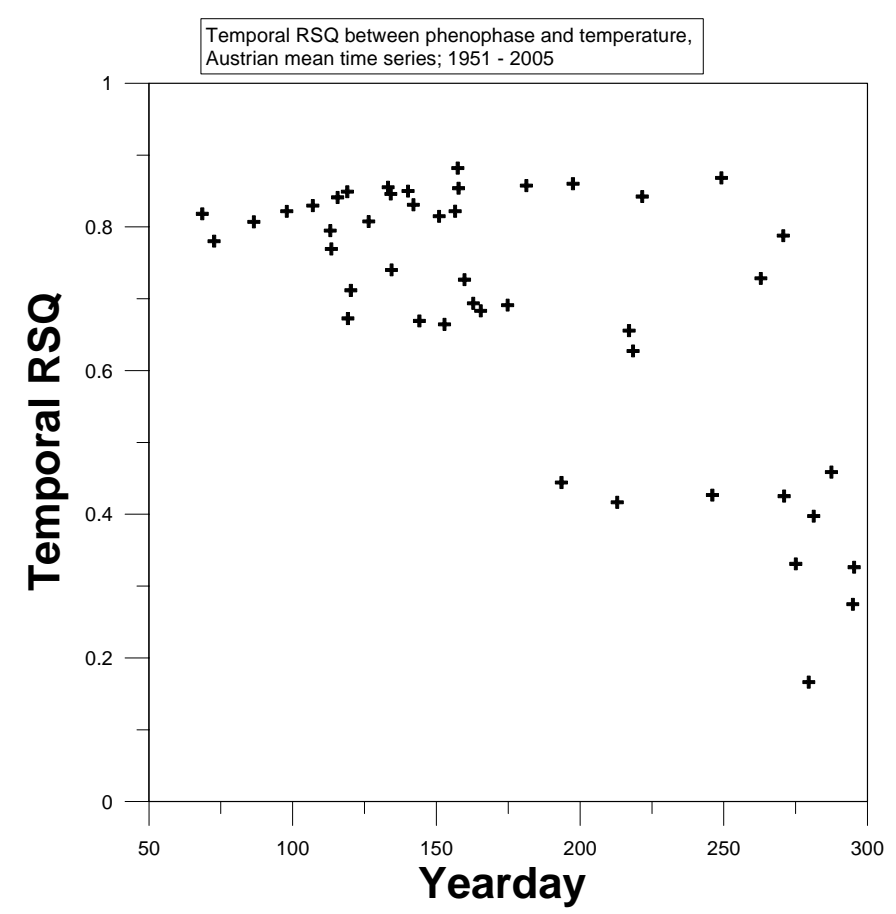

Abb 5: Streuplot der gemeinsamen zeitlichen Varianz zwischen der Temperatur Tp und den phänologischen Zeitreihen gemittelt über alle Stationen.

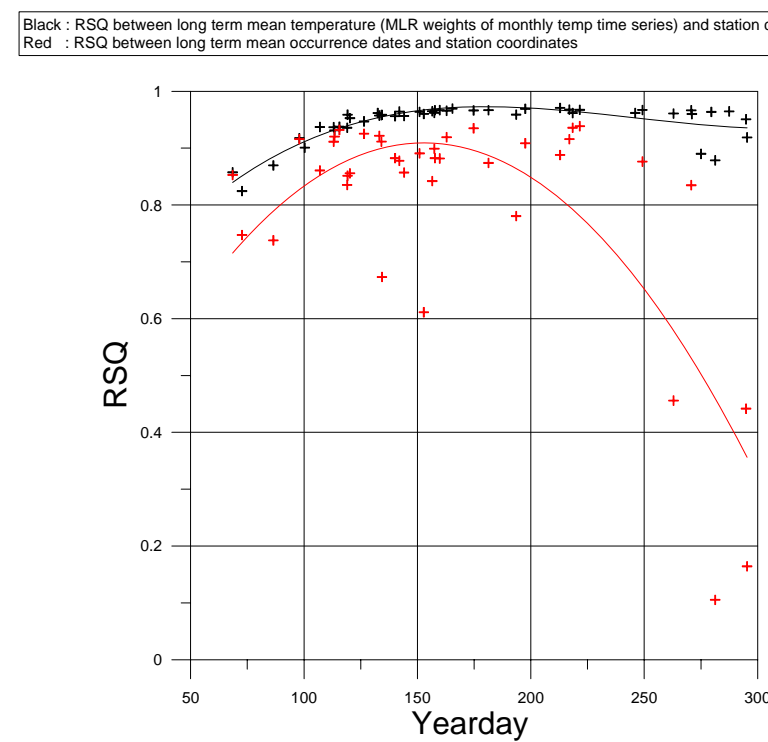

Abb. 6: Die durch das MLR - Modell erklärte räumliche Varianz der langjährigen mittleren Eintrittsdaten bzw. Der dazugehörigen langjährigen mittleren Temperatur Tp als Funktion der Stationskoordinaten. 

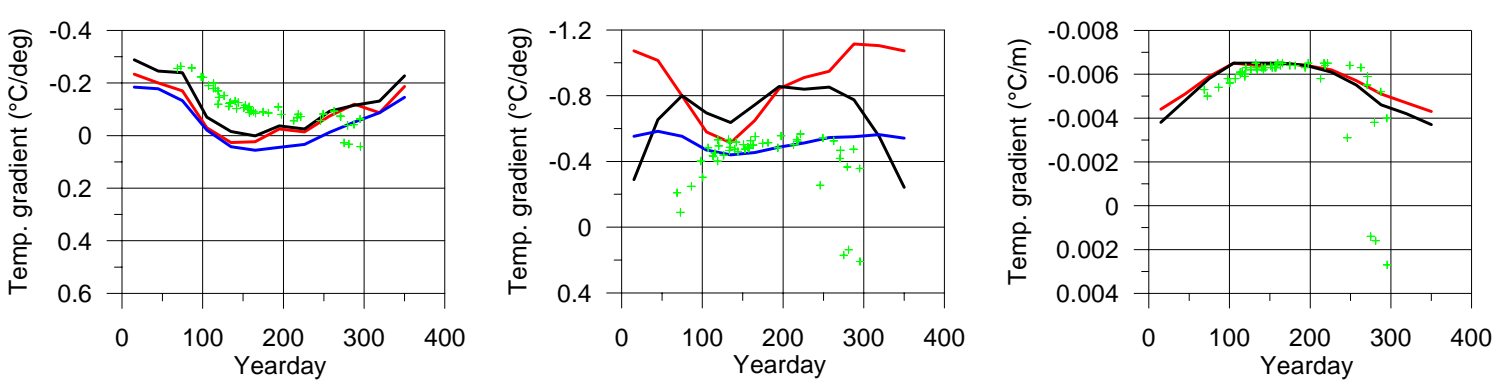

Black: Multiple linear regression, mean HISTALP temperature at HISTALP stations, 1951-2005 versus station lamda (left), phi (middle), zet (right), completed pheno time series Red: as above, but for the total HISTALP area

Blue: as above, but for EUROPE with CRU $5^{\circ} \times 5^{\circ}$ data

Abb. 7: Räumliche Gradienten der Temperatur diverser Temperaturmessnetze: österreichische HISTALP Temperaturstationen (Schwarz), alle HISTALP Temperaturstationen (rot); europäische CRU Stationen (blau) und die Temperatur Tp modelliert an den phänologischen Stationen der ZAMG (grün), geografische Länge (links), Breite (Mitte) der Station und Stationshöhe (rechts).

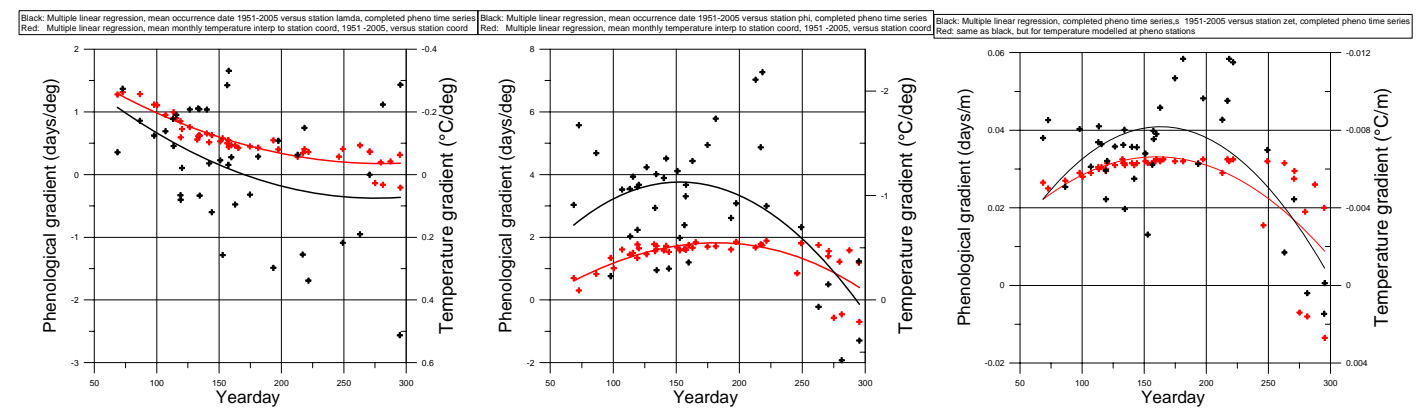

Abb. 8: Räumliche Gradienten der langjährigen mittleren Eintrittstermine der phänologischen Phasen (schwarz) verglichen mit der langjährigen mittleren monatlichen Temperatur Tp (rot). Dargestellt sind die Koeffizienten des räumlichen MLR Modells mit dem Längengrad der Station (links), dem Breitengrad der Station (Mitte) und der Stationshöhe (rechts).

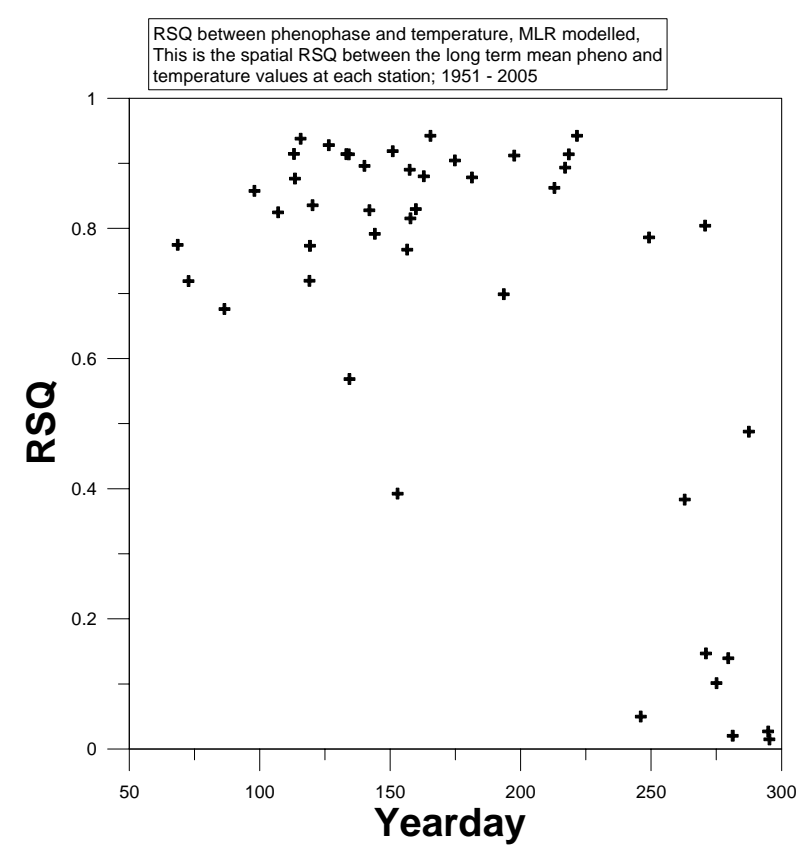

Abb. 9: Die gemeinsame räumliche Varianz zwischen den langjährigen mittleren Eintrittsdaten der phänologischen Phasen und der Temperatur. 

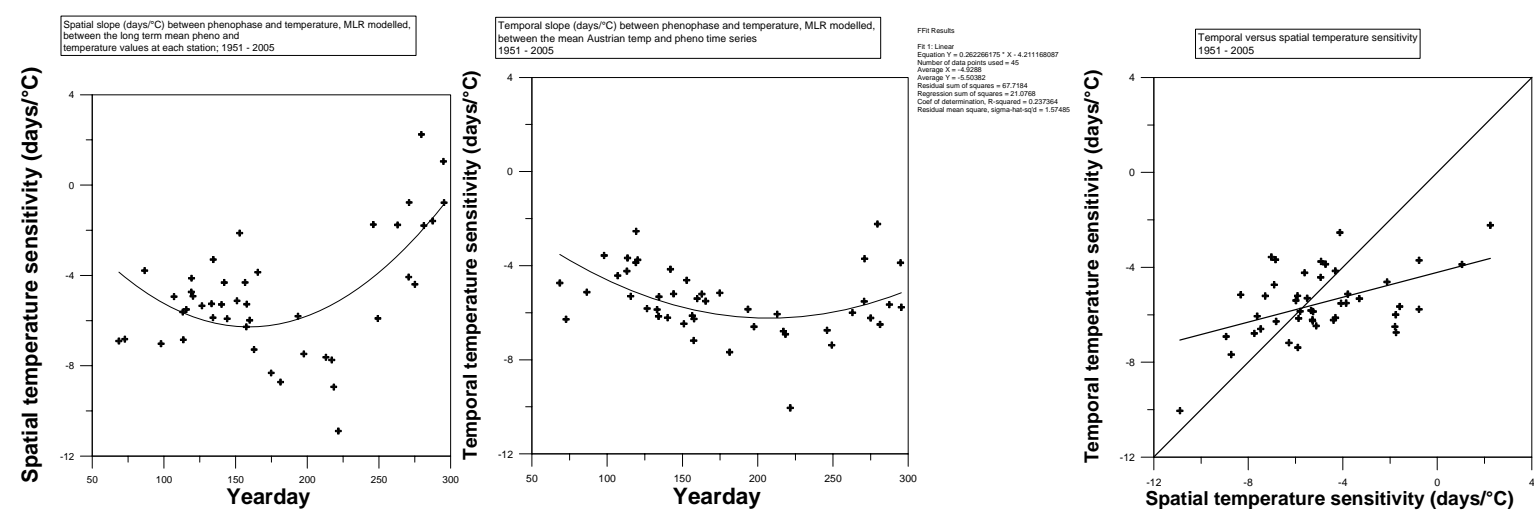

Abb. 10: Räumliche (links) und zeitliche (Mitte) Temperaturempfindlichkeit der Eintrittsdaten phänologischer Phasen. Streuplot zwischen der räumlichen und zeitlichen Temperaturempfindlichkeit der Eintrittsdaten phänologischer Phasen (rechts).

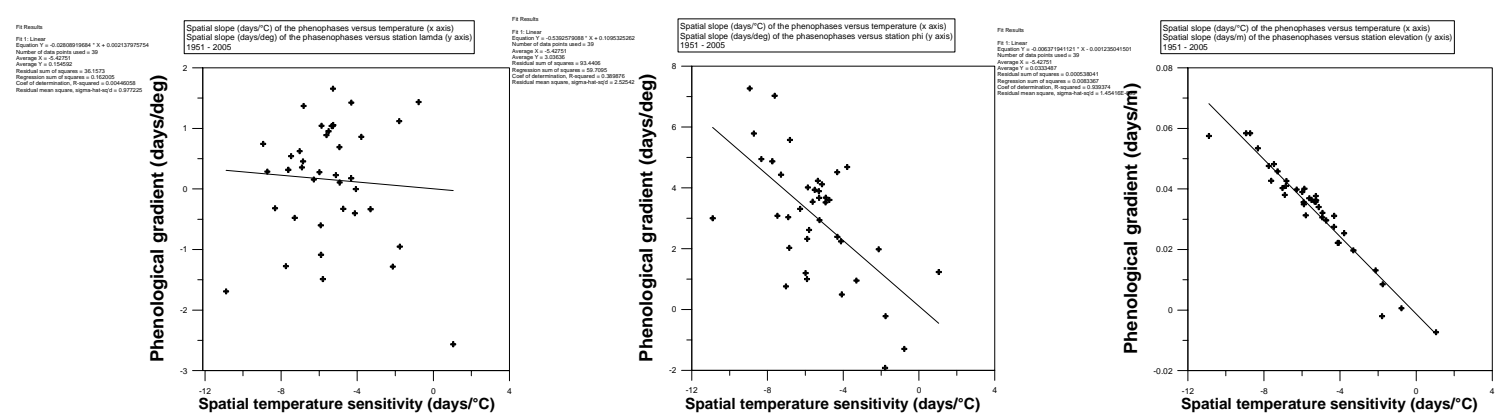

Abb. 11: Streuplots der räumlichen Temperaturempfindlichkeit der phänologischen Phasen als Funktion der räumlichen phänologischen Gradienten bzw. der räumlichen Empfindlichkeit der Phasen (Längengrad der Station links, Breitengrad der Station Mitte und Stationshöhe rechts).

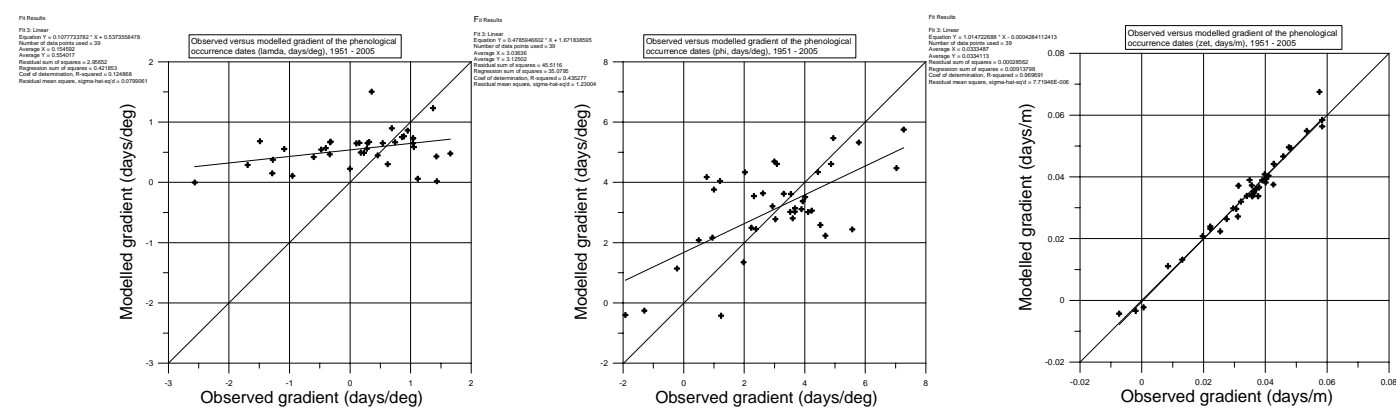

Abb. 12: Streuplot der modellierten räumlichen Gradienten als Funktion der beobachteten räumlichen Gradienten der langjährigen mittleren Eintrittszeiten phänologischer Phasen (Längengrad der Station links, Breitengrad der Station Mitte und Stationshöhe rechts).
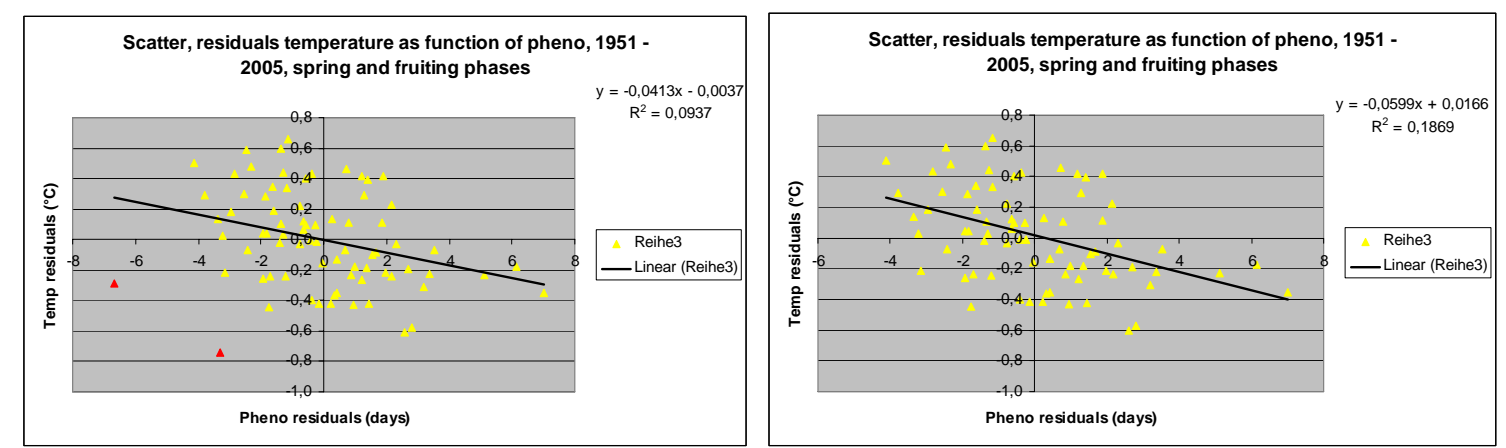

Abb. 13: Streuplots der MLR Modell Residuen (modelliert - beobachtet) der mittleren langjährigen phänologischen Eintrittsdaten gegen die MLR Modell Residuen (modelliert - beobachtet) der Temperatur $T p$. In der rechten Abbildung wurden die beiden Ausreißer entfernt. 

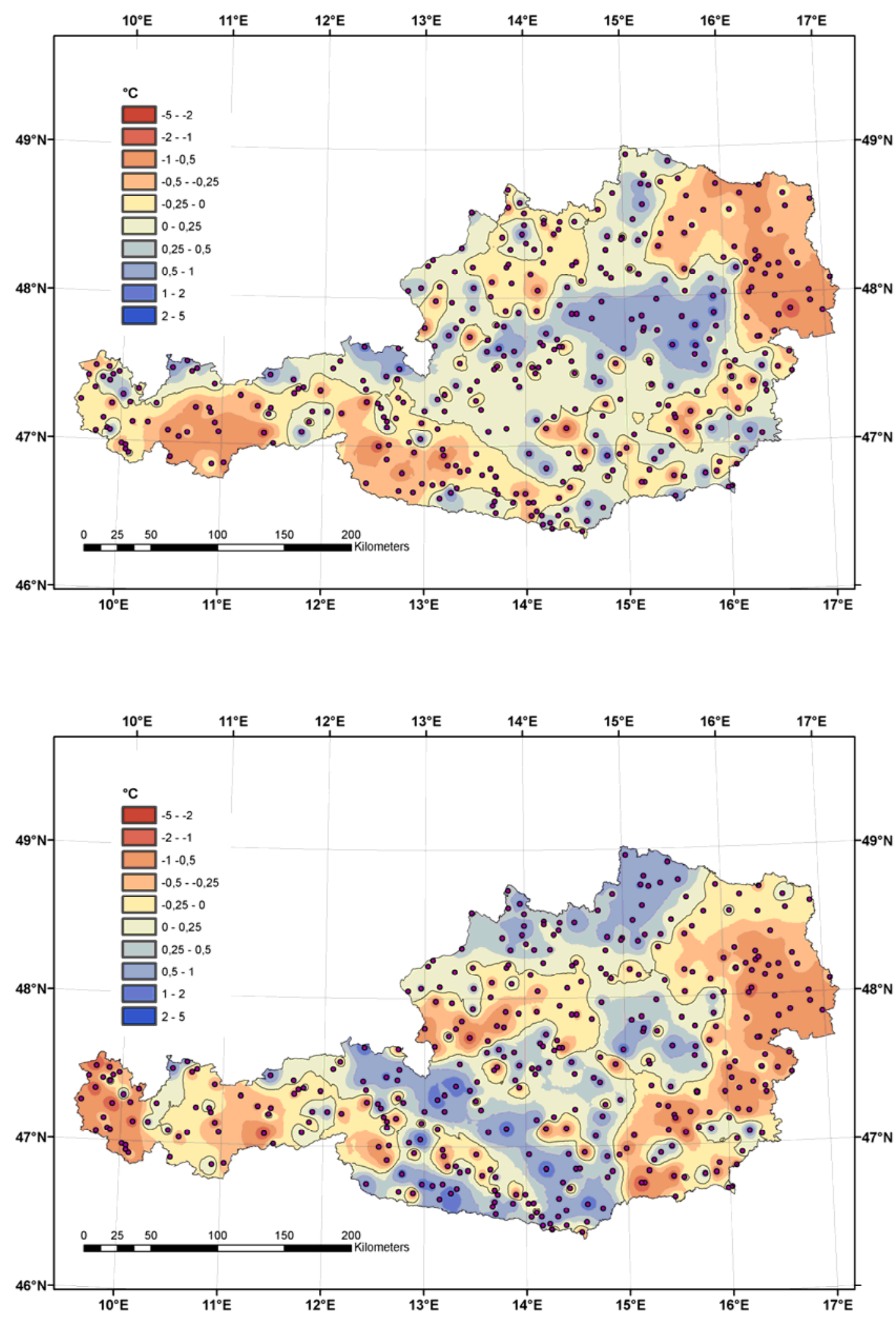

Abb. 14: Residuen der ECSN Temperaturdaten Österreichs (386 Stationen), 1961 - 1990, für das Sommerhalbjahr (oben) und das Winterhalbjahr (unten). 

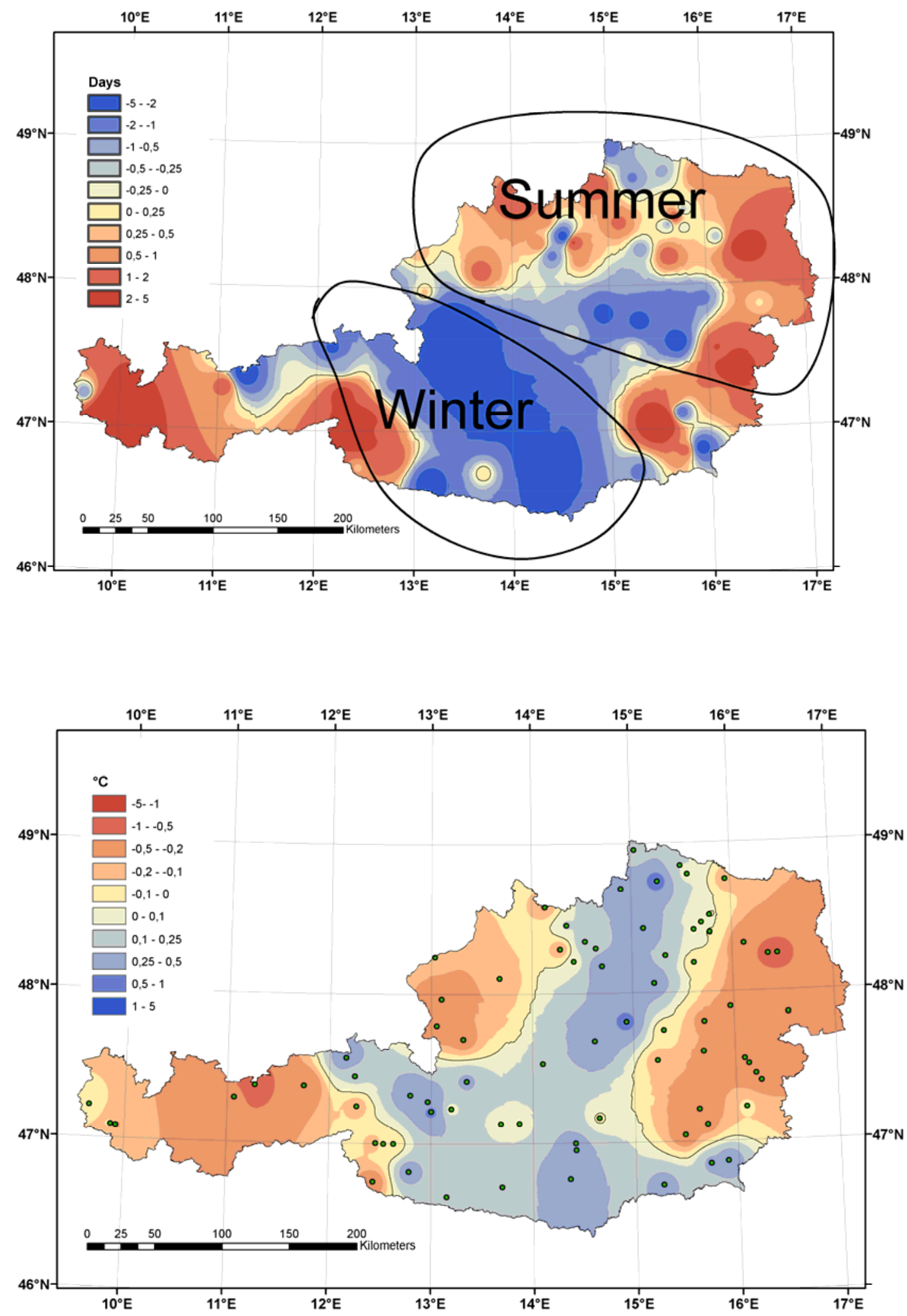

Abb. 15: Residuen von bis zu 21 ausgewählten Phasen (oben) und der dazugehörenden Temperaturen $T p$ (unten) (1951 - 2005). 

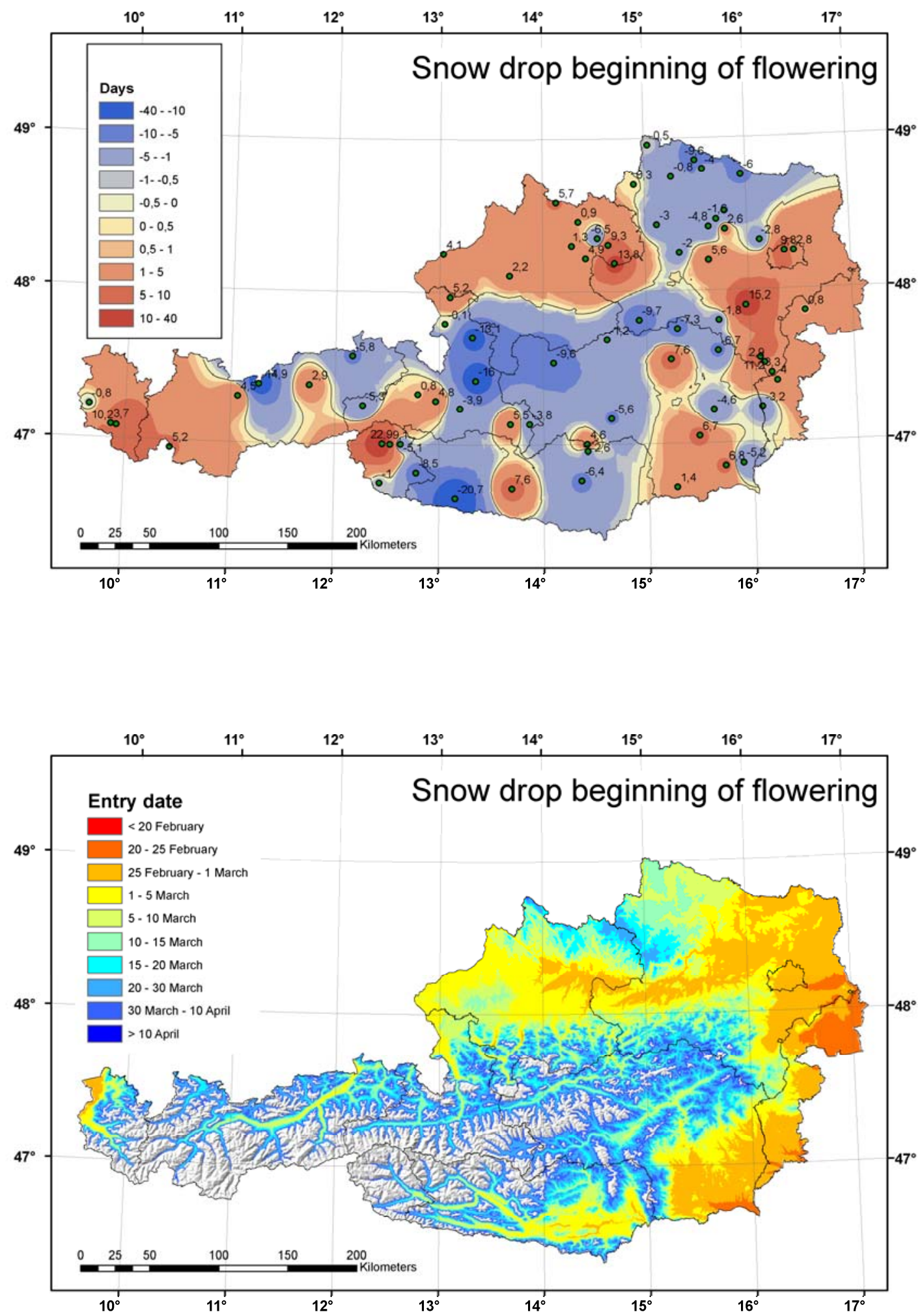


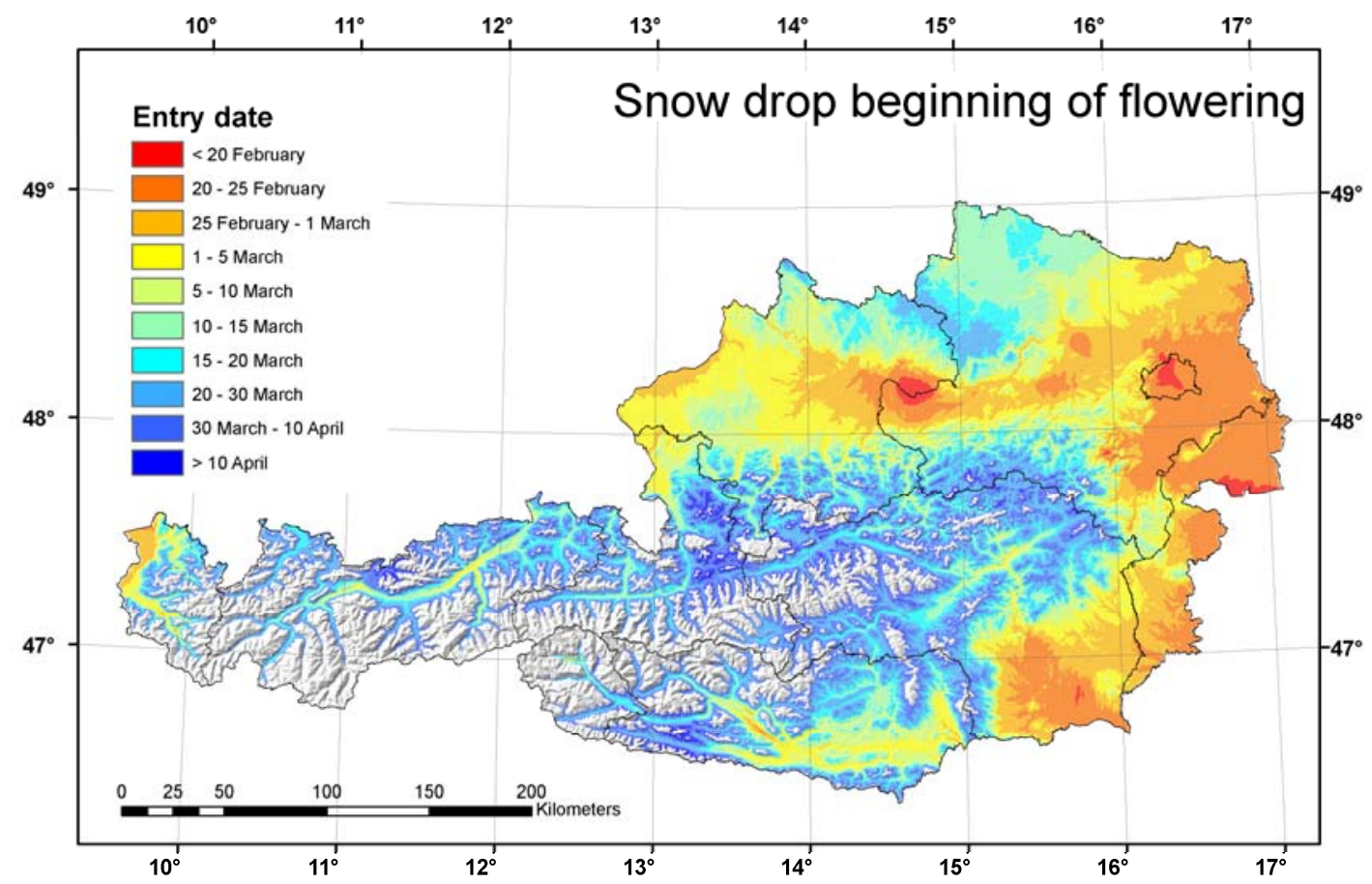

Abb. 16: Residuenkarte (oben), Karte der langjährigen mittleren Eintrittszeiten hergestellt auf Grundlage des räumlichen MLR - Modells (Mitte) und Karte der langjährigen mittleren Eintrittszeiten interpoliert mit dem MLR - Modell in Kombination mit den Residuen (unten), Schneeglöckchen Beginn der Blüte, $1951-2005$. 

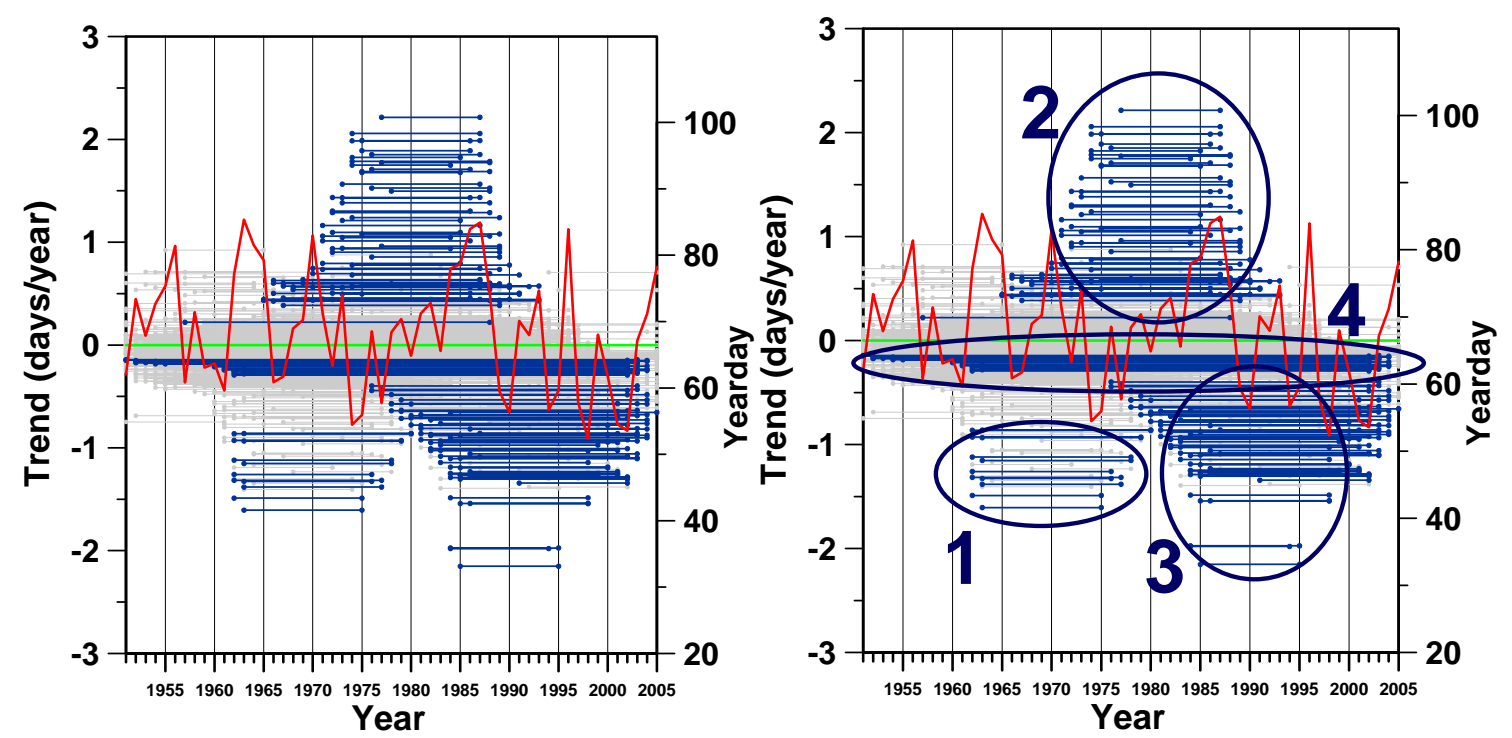

Abb. 17: Trends der mittleren österreichischen Zeitreihe ,Schneeglöckchen Beginn der Blüte' (rot) dargestellt durch Balken, die den Zeitraum überspannen, für den der Trend berechnet wurde $(x-$ Achse); die Trendwerte können an der y - Achse abgelesen werden. Signifikante Trends (nach Mann - Kendall) sind dunkelblau, nicht signifikante Trends hellgrau; die Minimalzahl der Jahre, für die Trendwerte berechnet wurden, beträgt 10 Jahre.
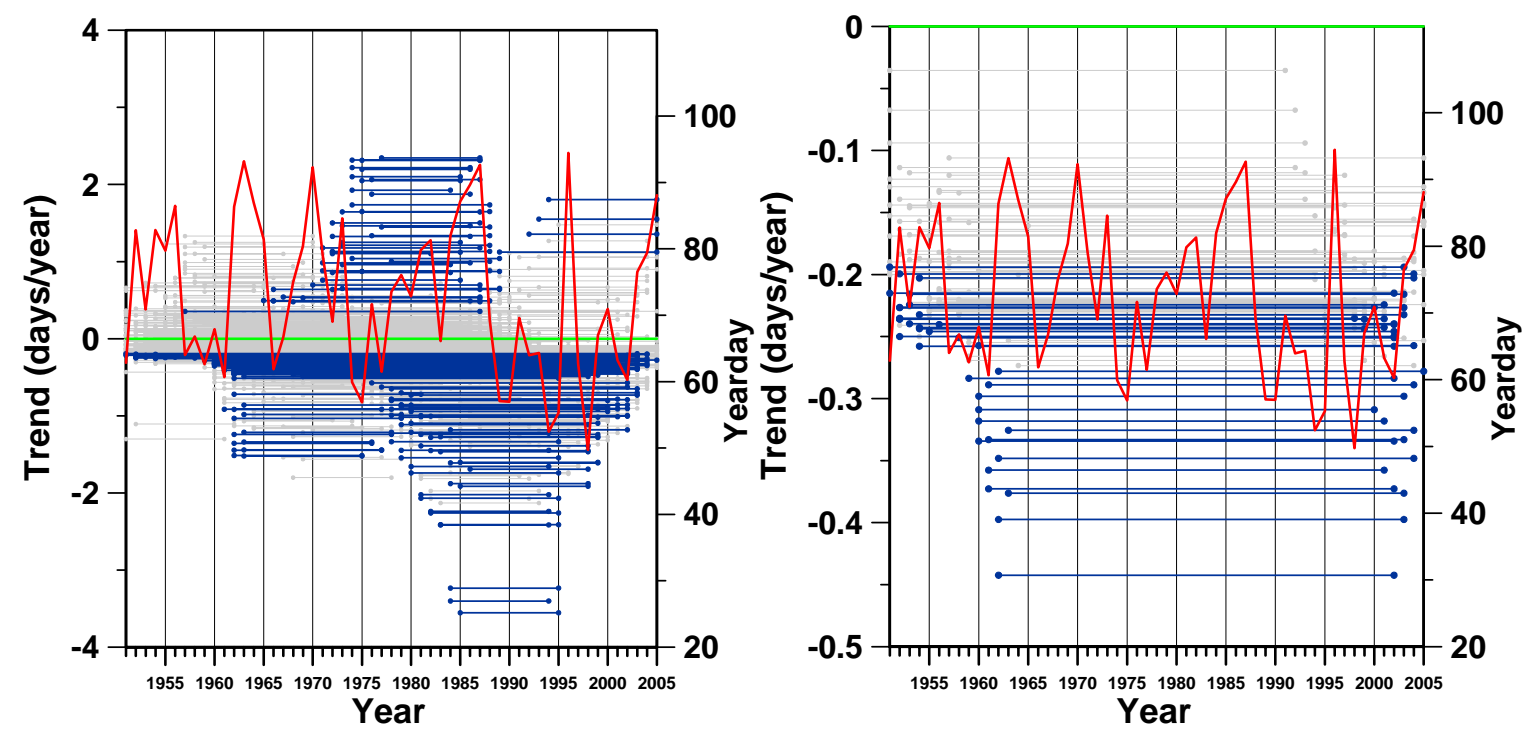

Abb. 18: Trends der mittleren österreichischen Zeitreihe „Haselstrauch Beginn der Blüte' (rot) dargestellt durch Balken, die den Zeitraum überspannen, für den der Trend berechnet wurde $(x-$ Achse); die Trendwerte können an der y - Achse abgelesen werden. Signifikante Trends (nach Mann - Kendall) sind dunkelblau, nicht signifikante Trends hellgrau; die Minimalzahl der Jahre, für die Trendwerte berechnet wurden, beträgt 10 Jahre (links) und 40 Jahre (rechts). 

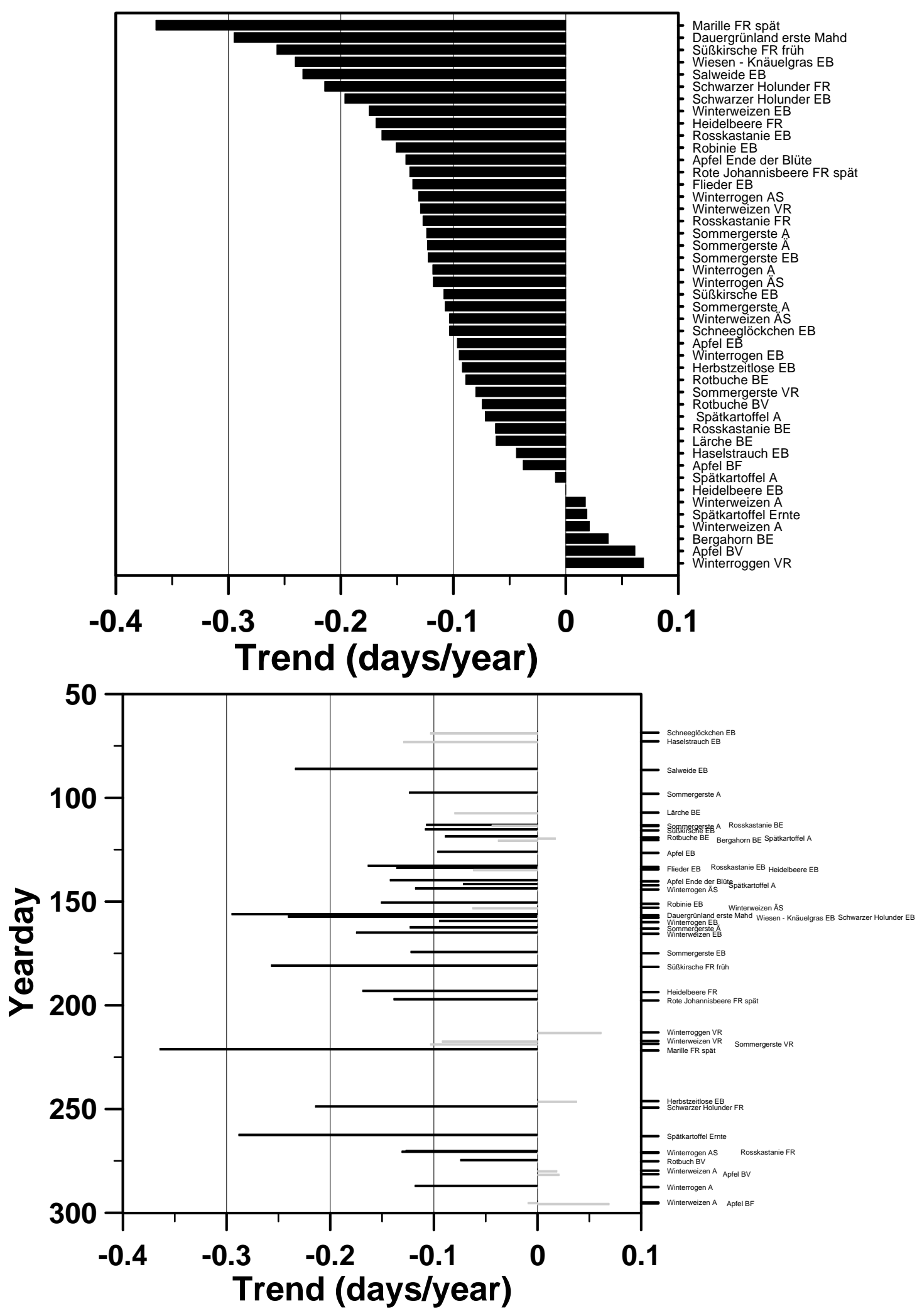

Abb. 18: Trends (1951 - 2005) von 45 ausgewählten phänologischen Phasen, sortiert nach dem Trendwert (oben) und nach dem mittleren langjährigen Eintrittsdatum (unten). Signifikante Trends (90\% Niveau nach Mann - Kendall) sind schwarz, nicht signifikante Trends sind grau (BE Blattentfaltung, EB Erste Blüte, ÄS Ährenschieben, VR Vollreife, FR Fruchtreife, BV Blattverfärbung, BF Blattfall, A Austrieb). 


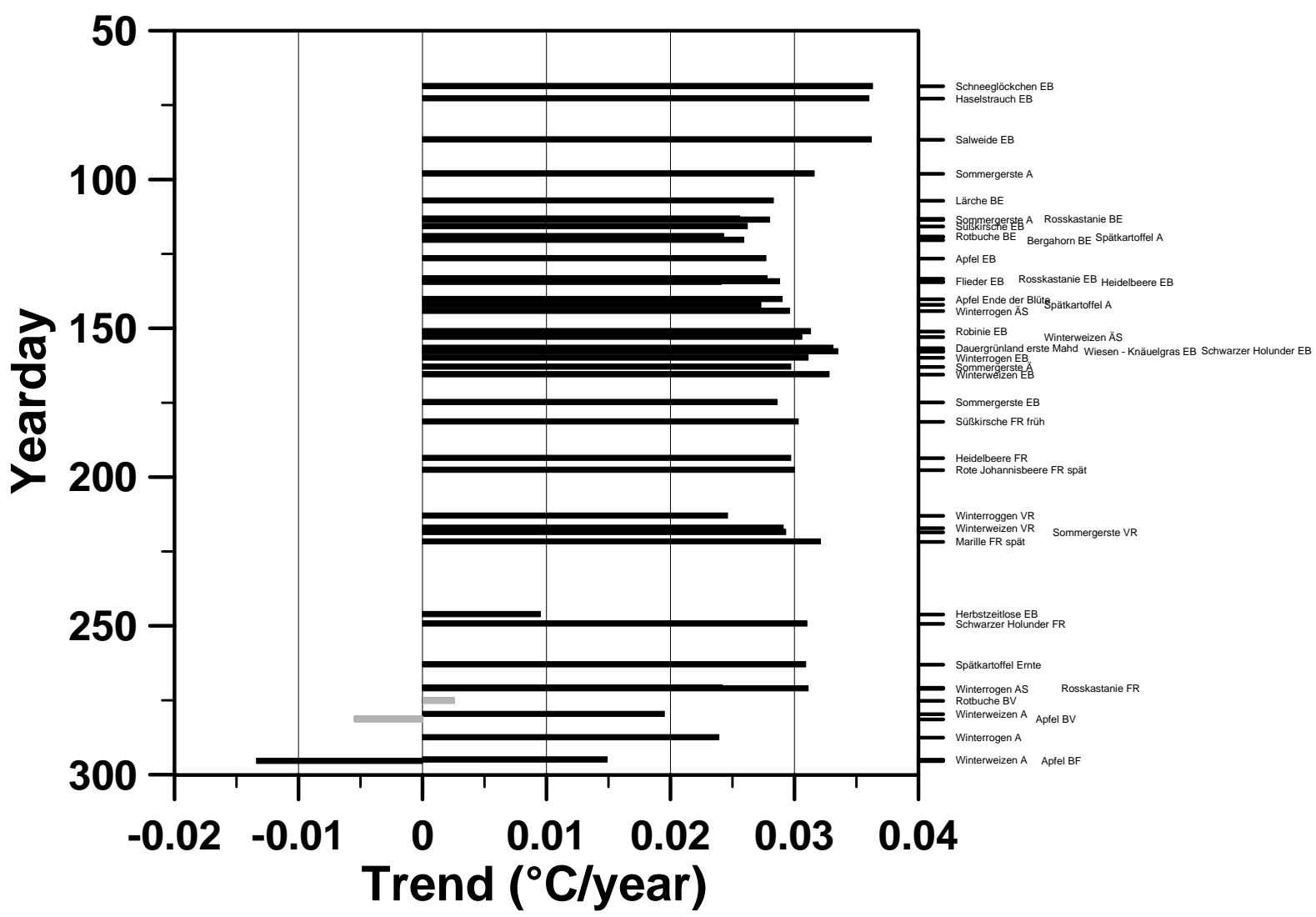

Abb. 19: Trends (1951 -2005) der Temperaturzeitreihen von Tp. Signifikante Trends (90\% Niveau nach Mann - Kendall) sind schwarz, nicht signifikante Trends sind grau (BE Blattentfaltung, EB Erste Blüte, ÄS Ährenschieben, VR Vollreife, FR Fruchtreife, BV Blattverfärbung, BF Blattfall, A Austrieb).
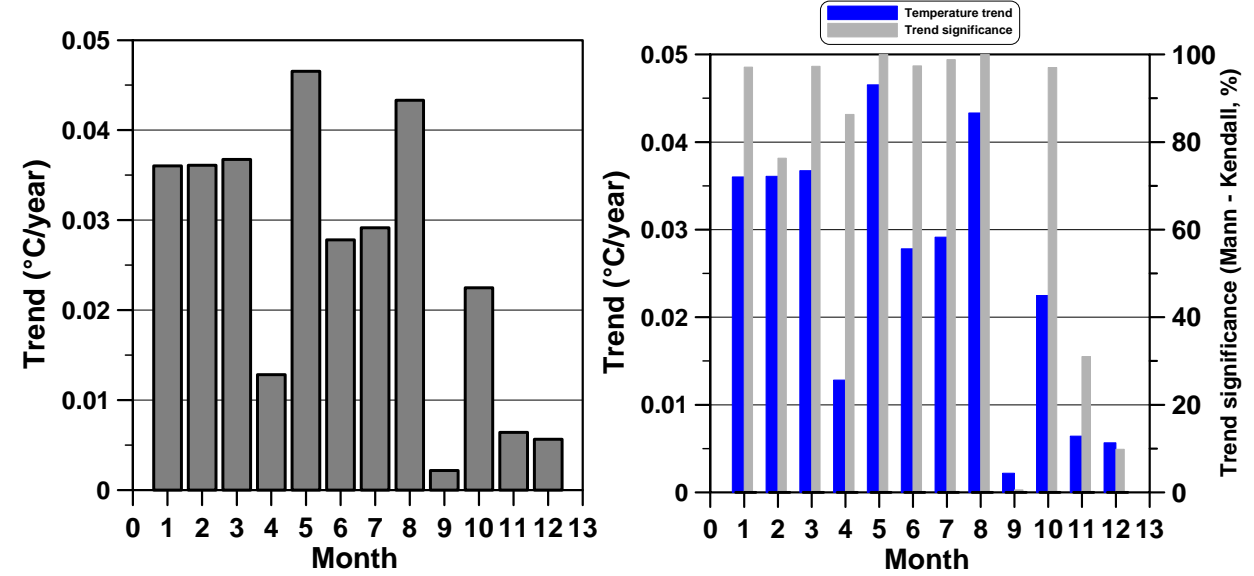

Abb. 20: Trends (1951 -2005) der mittleren monatlichen Temperaturzeitreihen an den phänologischen Stationen (links, rechts mit Trend Signifikanz nach Mann - Kendall). 


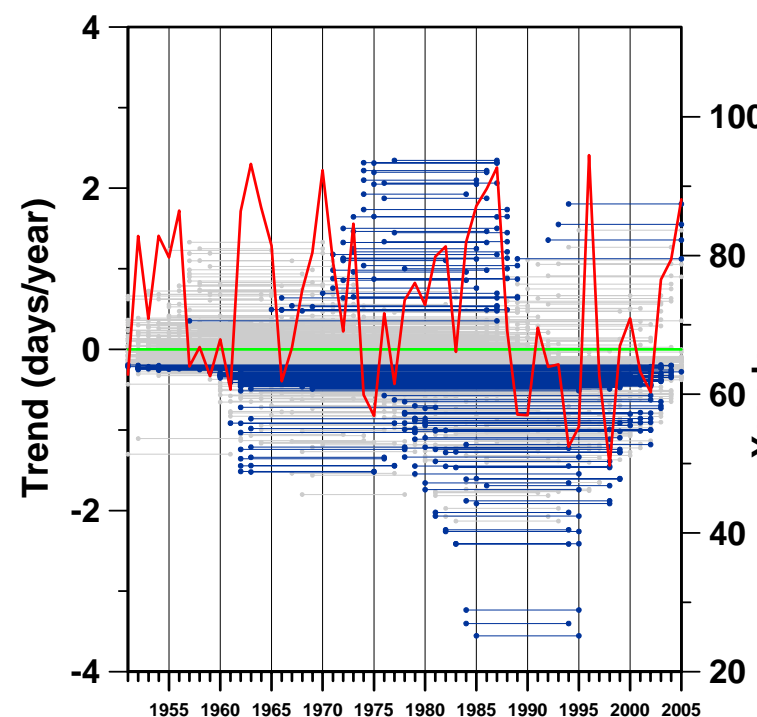

1

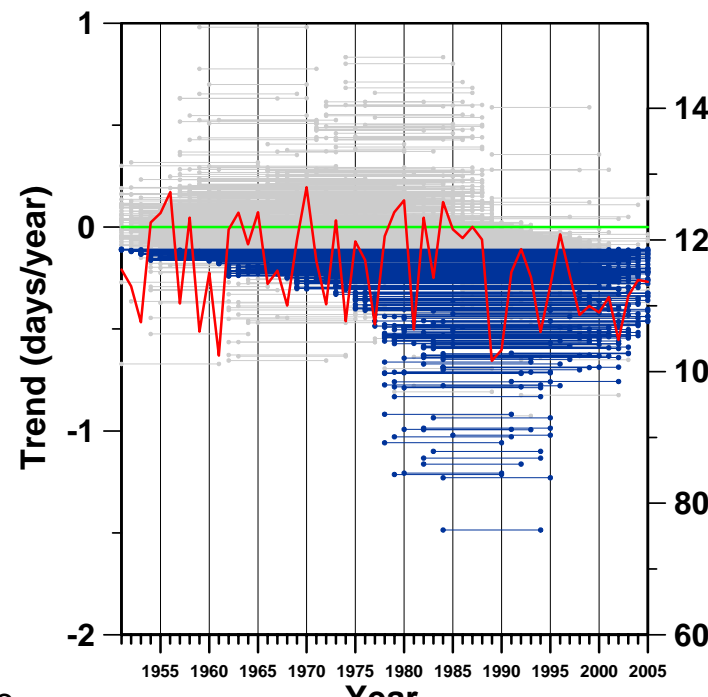

3

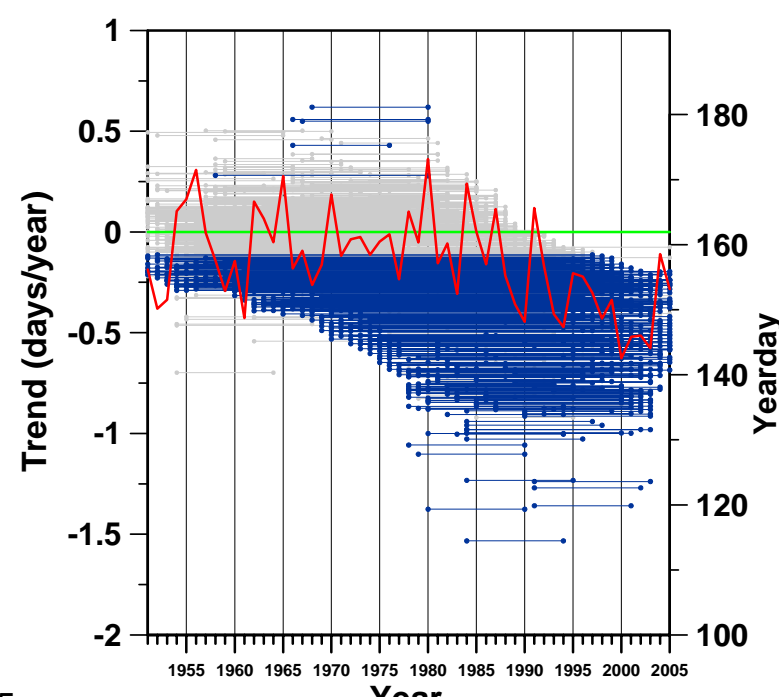

5
Year 2

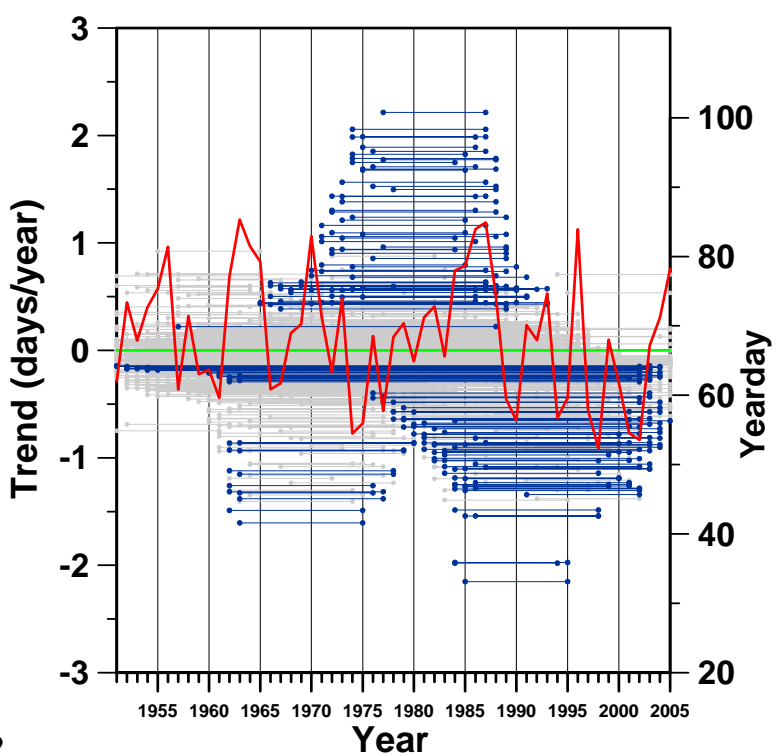

Year

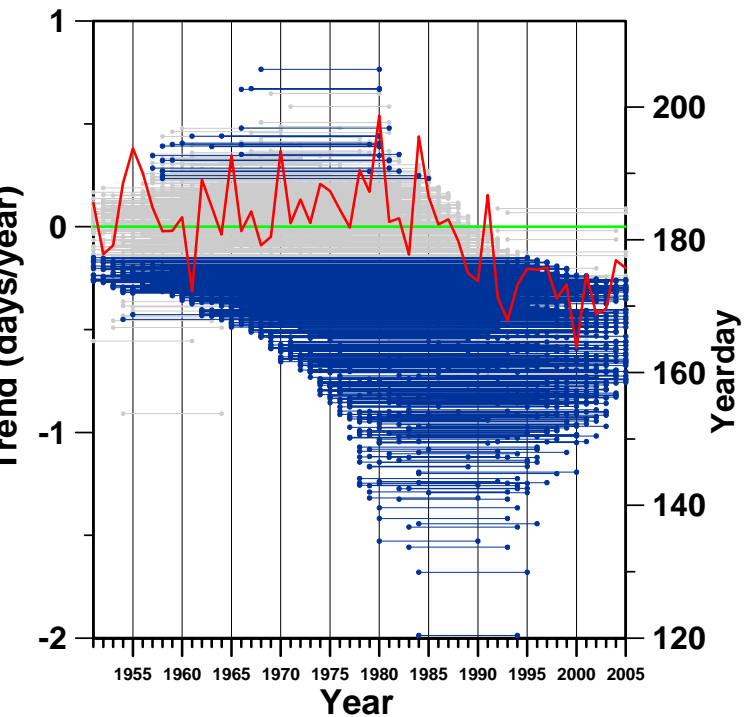
Year

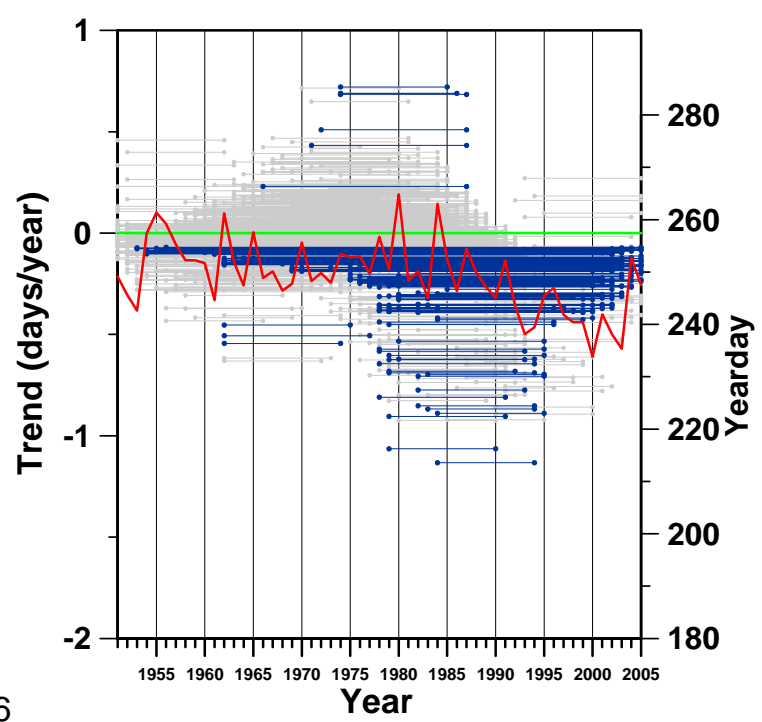



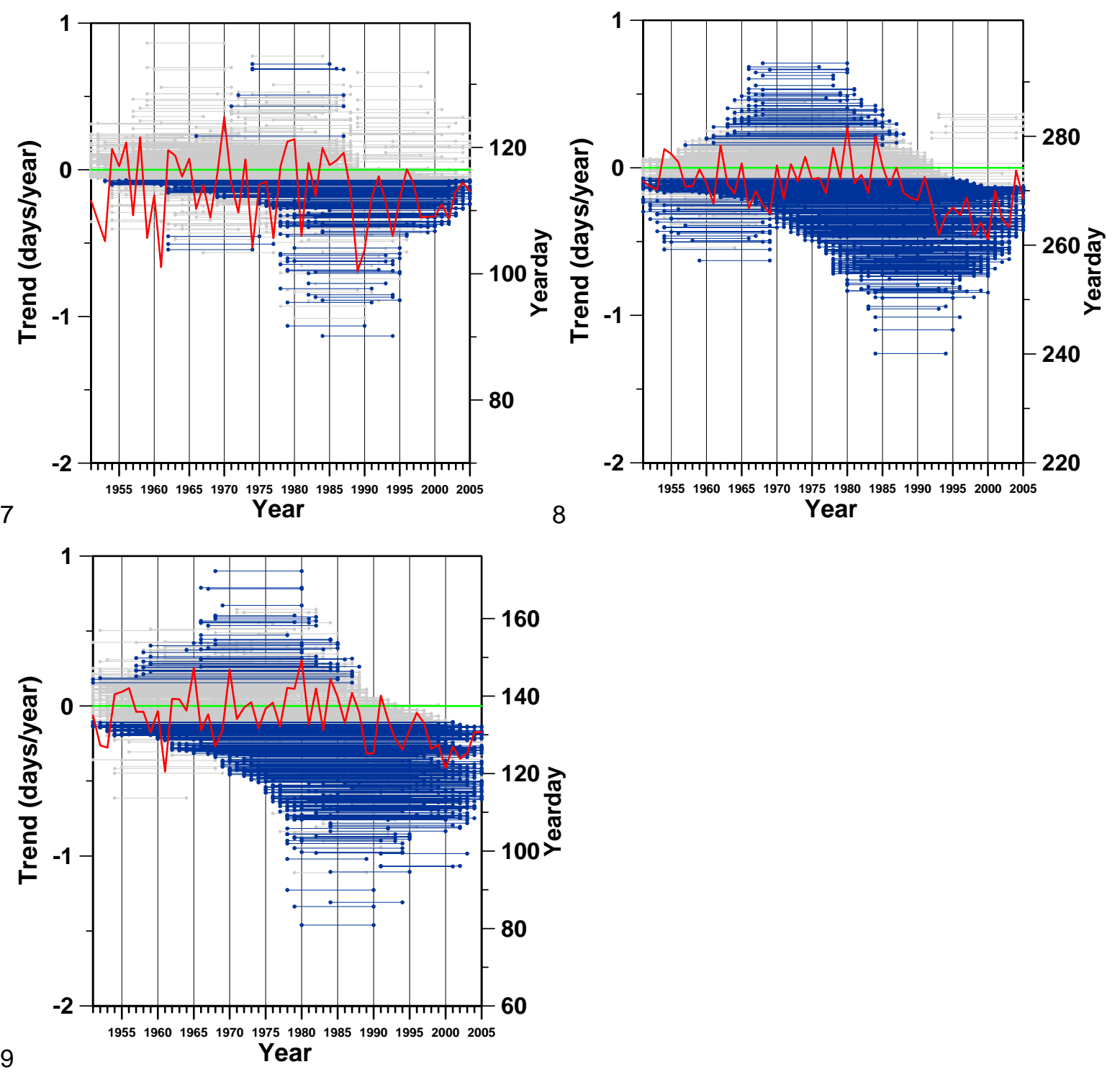

Abb. 21: Trends mittlerer österreichischer Zeitreihen von

1 Hasel EB
3 Kirsche EB
5 Schwarzer Holunder EB
7 Rosskastanie EB
9 Flieder EB

2 Schneeglöckchen EB

4 Kirsche FR

6 Schwarzer Holunder FR

8 Rosskastanie FR

dargestellt durch Balken, die den Zeitraum überspannen, für den der Trend berechnet wurde $(x-$ Achse); die Trendwerte können an der y - Achse abgelesen werden. Signifikante Trends (nach Mann - Kendall) sind dunkelblau, nicht signifikante Trends hellgrau; die Minimalzahl der Jahre, für die Trendwerte berechnet wurden, beträgt 10 Jahre. 

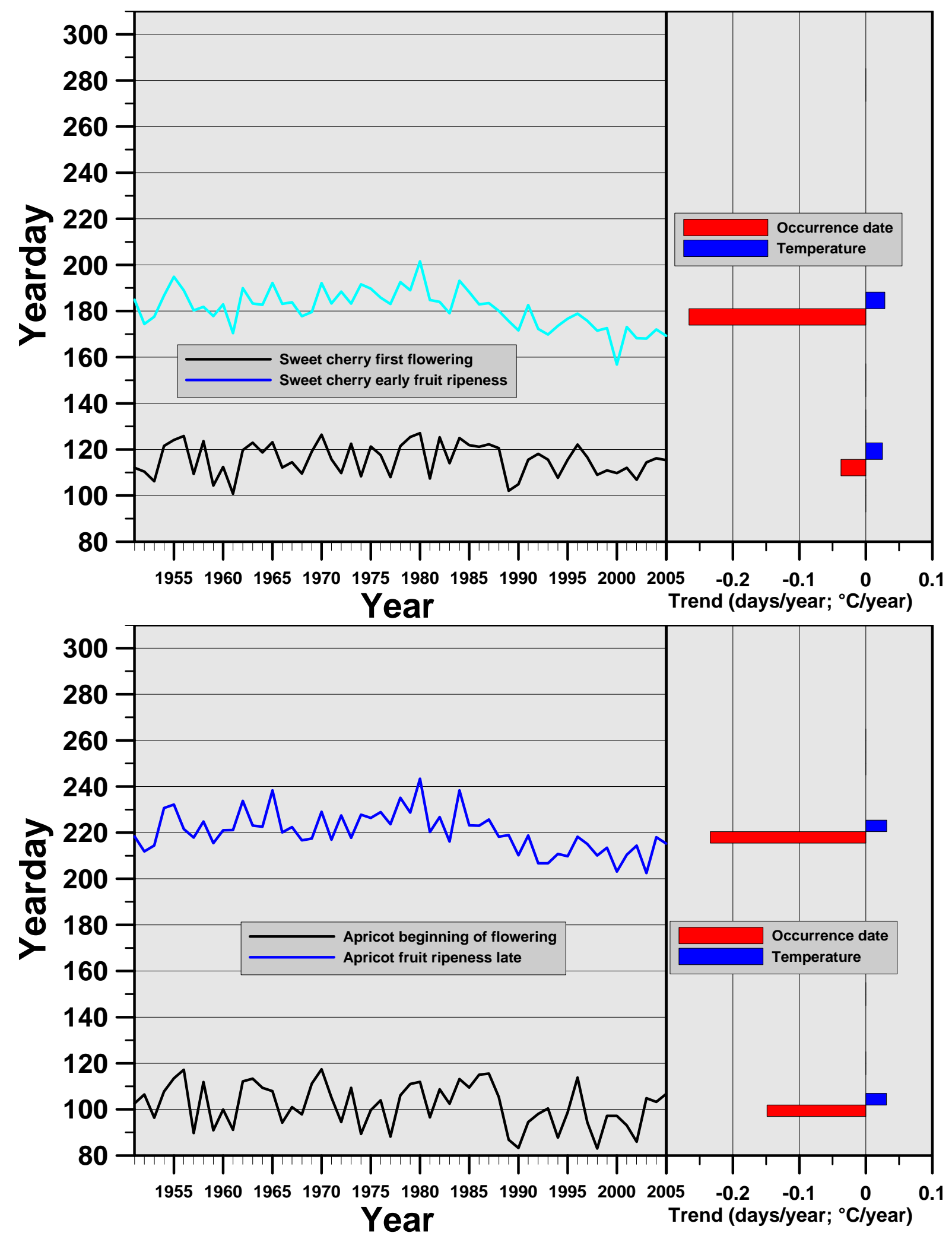

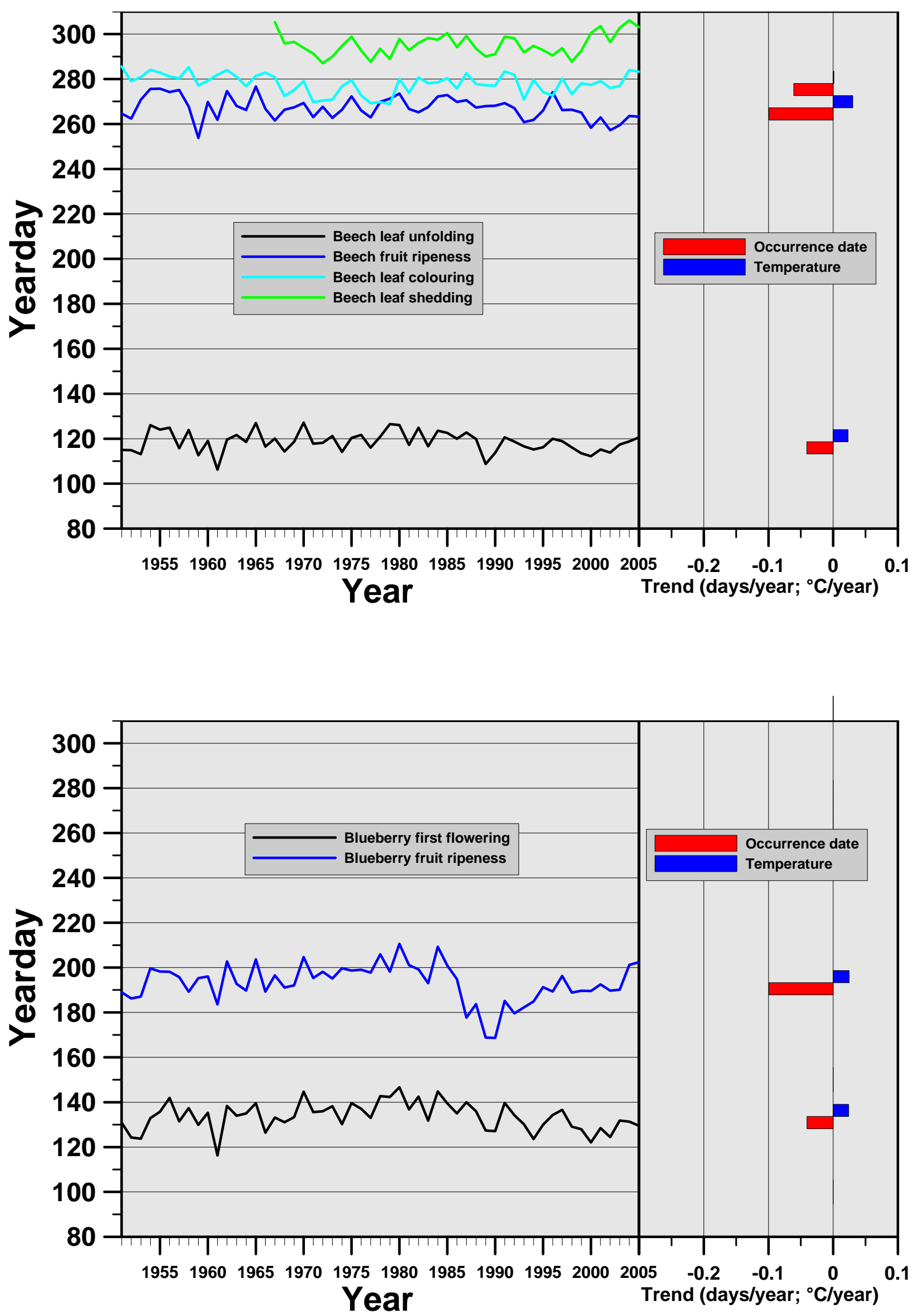

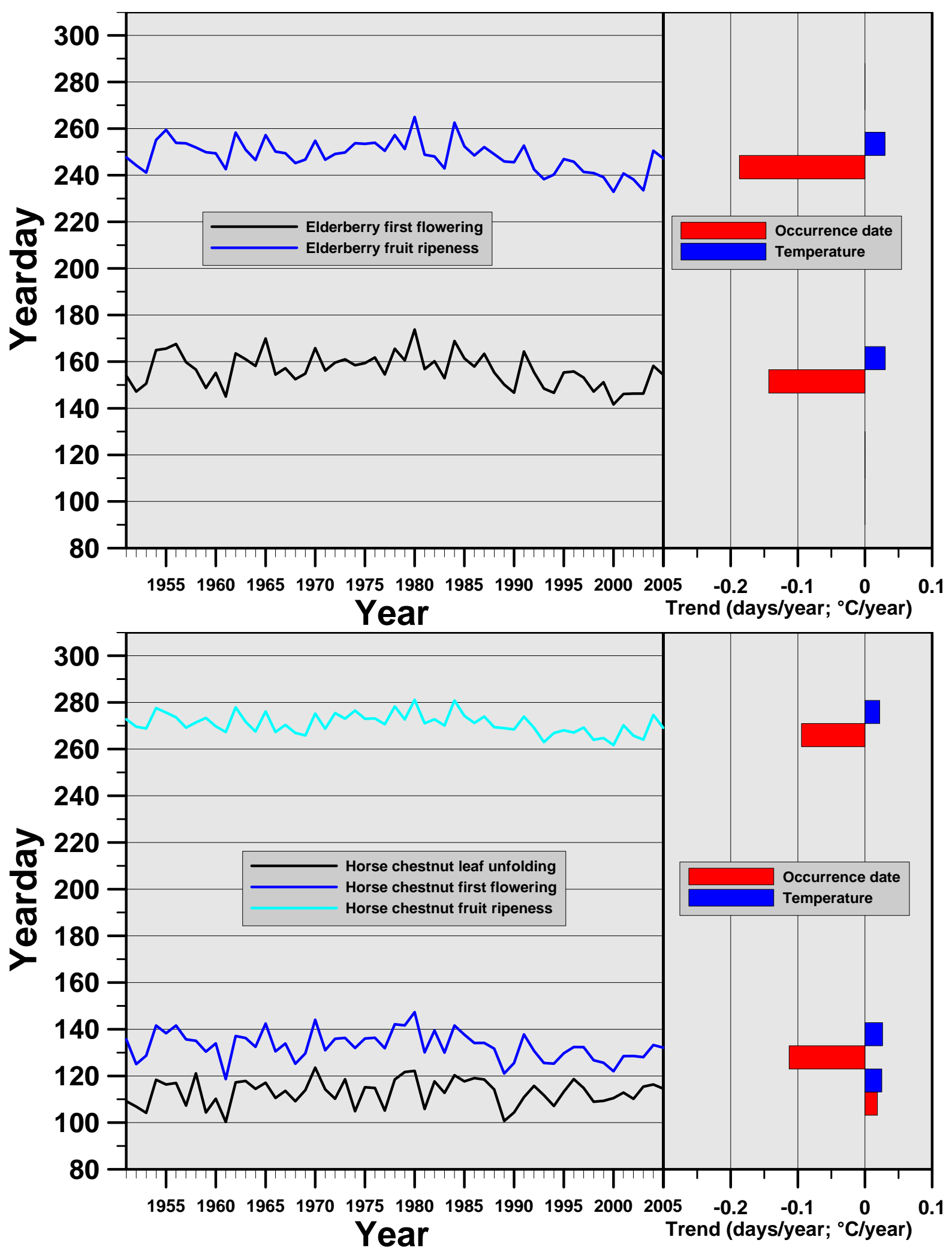


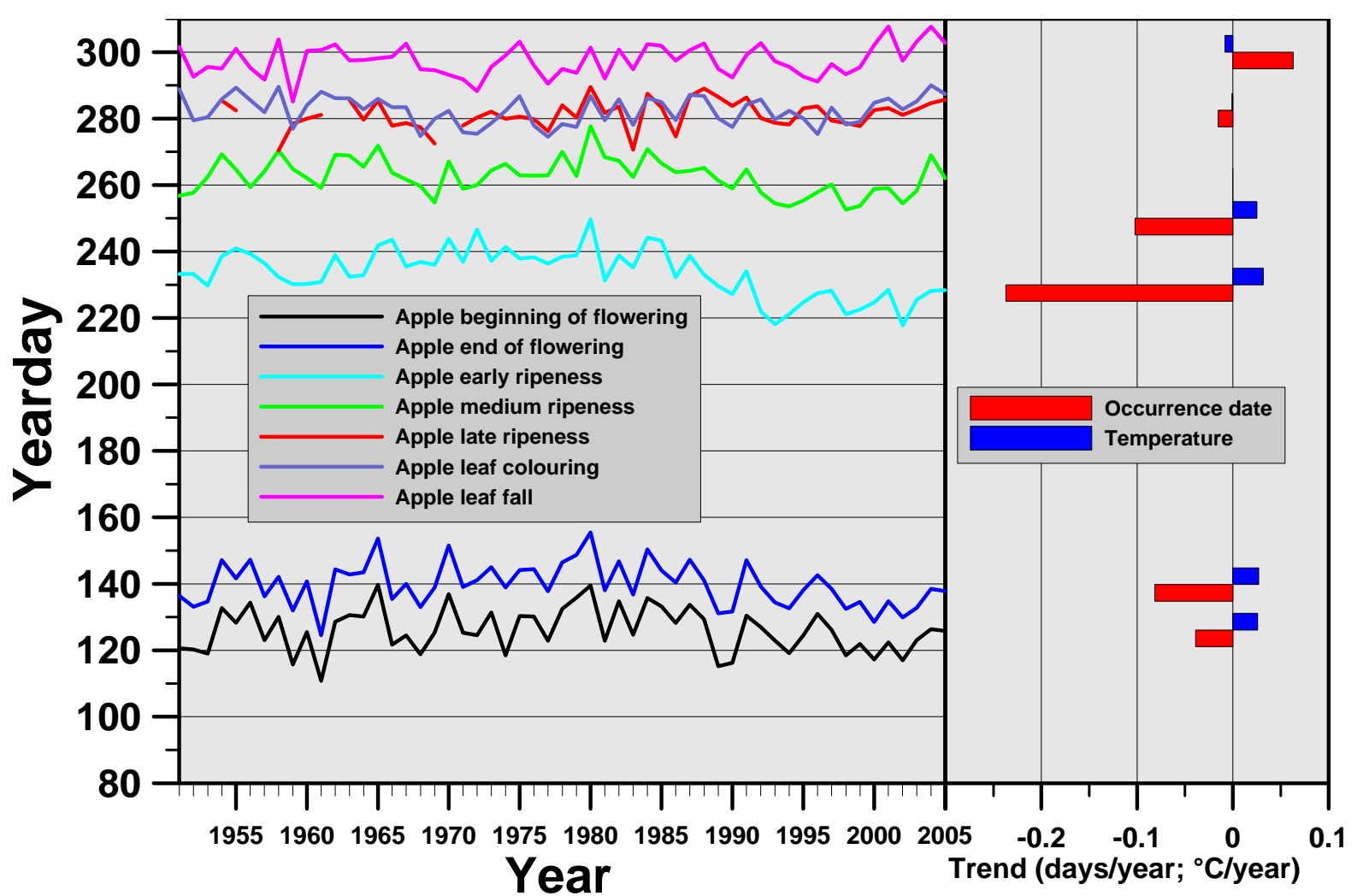

Abb. 22: Zeitreihen ausgewählter phänologischer Phasen, ihre Trends und die Trends der dazugehörigen Temperatur Tp.

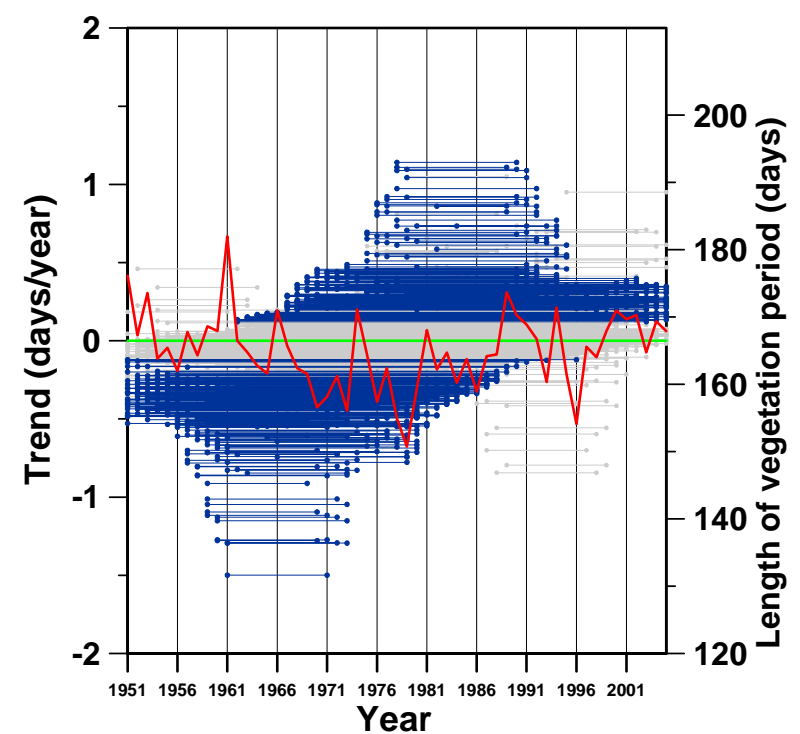

Abb. 23: Balkendarstellung der Trends der Zeitreihe der Vegetationsperiode $=7$ Laubaustriebsphasen - 2 Laubverfärbungsphasen (rote Kurve, weitere Details im Text). 